\title{
A New Intermittent Pumping Design for Fluid Shortage Wells
}

\author{
Xingyuan Liang, Fujian Zhou \& Tianbo Liang* \\ Low oil price requires oil companies to reduce costs and increase benefits. The wells with deficient fluid \\ supplies approximately account for $20-30 \%$ of all producing wells, and this situation is even worse \\ in the old oilfields. Intermittent production is an effective way to reduce the cost and increase the \\ system efficiency to overcome the shortage of oil supply from the reservoir. The key is to optimize the \\ intermittent pumping scheme, i.e., to design reasonable shut-in and operating periods. In this study, \\ this is achieved using the dynamic change of the fluid level in the wellbore. From the electrical power \\ curve to the dynamometer card, the dynamic drop of the fluid level can be obtained, and thus the \\ optimal operation time of the well; at last, from the inflow performance of the well, the optimal shut-in \\ period can be obtained. This method shows a good application in the field through a case study.
}

To face the severe situation with the low oil prices, most oil field operators have taken actions to reduce the expenditure and improve their benefits. There are a lot of wells experiencing a fluid shortage in China, and the intermittent pumping can be an effective solution for these wells ${ }^{1}$. When operating the intermittent pumping, the pump runs when liquid in the annulus is sufficient, while it stops when the liquid in the annulus is insufficient ${ }^{2}$. This operation can reduce the energy consumption, improve the pump efficiency, and alleviate the abrasion between the pump and casing. To ensure a successful intermittent pumping, the key is to determine the duration of operation and shut-in periods. Currently, this can be achieved using four methods as follows.

The first method is to use the fluid-buildup curve $e^{3,4}$. The optimal operation and shut-in period can be obtained by analyzing the good selected and the characteristics of the buildup curve of each selected well ${ }^{5}$. And it cannot be calculated automatically. The second method is to use the production decline curve $e^{6,7}$. According to the porosity of reservoir rock and the production history of the well, the intermittent-pumping can be designed based on the distribution of annulus inflow performance and the buildup test ${ }^{7}$. Many factors have an impact on the curve, so the accuracy is needed to be further enhanced. The third method is to use the economical limitation, where the optimal period is obtained by conducting the material balance and break-even analysis ${ }^{8}$. But there are many parameters involved. The last method is building the analytical model, where the intermittent pumping scheme is obtained by using the inflow performance and the material balance of the well. And this method also needs a liquid recovery curve. Most of the fluid shortage wells in the oil field are operated at the same intermittent pumping scheme for a long period time. However, inflow performance is different for each well in different periods, and thus the intermittent pumping should be different for each well and changed according to production needs ${ }^{9}$. Based on material balance, exponential expressions of the shut-in and production periods have been established ${ }^{10}$. Besides, based on the production test and the variation rate of the casing pressure, the intermittent time can be determined ${ }^{11}$. A reduced pressure has been defined and an initial intermittent pumping scheme has also been figured out. Based on the scheme, a model on the change of annulus fluid level with time has been built. Moreover, the fluid buildup curve and the optimized intermittent pumping for fluid shortage wells have been obtained $^{1}$. The dynamic fluid level is observed by the acoustic waves in the above methods. However, the collecting data of acoustic waves by a human is not continuous. Furthermore, monitoring data is important, which can help us adjust the intermittent pumping scheme in real-time.

In this study, a new method of intermittent pumping has been developed. First, gathered in real-time, the electrical parameters are used to interpret the surface dynamometer card; secondly, dynamic fluid depth is solved by the downhole dynamometer card, which can be converted from the surface dynamometer card; thirdly, during the shut-in period, the buildup curve can be drawn through the mathematical relationship between the inflow performance of wells and submergence; finally, the intermittent pumping can be obtained by the slope method. 


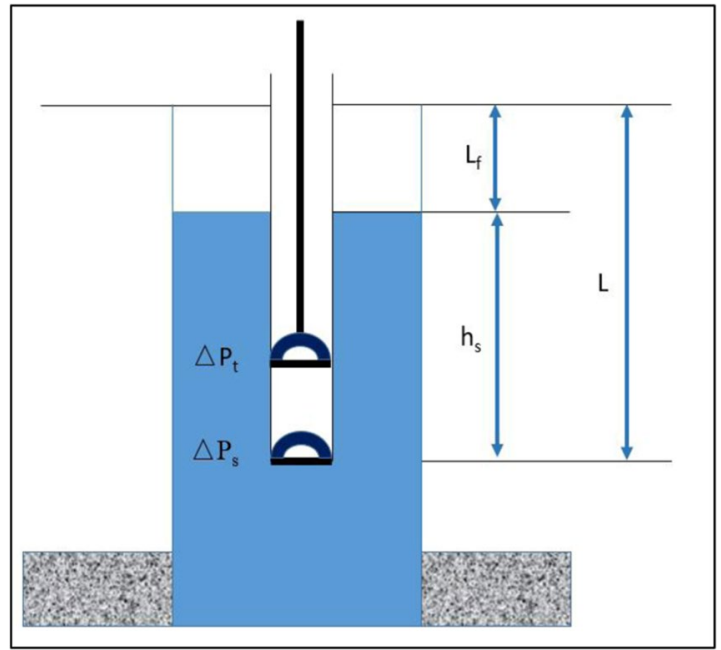

Figure 1. Locations of static and dynamic levels.

\section{Method: Optimization of Intermittent Pumping Scheme}

Using electrical power curve to get the surface dynamometer card. A working pumping unit (PU) can show different kinds of working patterns. Powered by electricity, the motor of the PU drives the horsehead up and down. Since the electrical energy is converted into mechanical energy, any change of stress at suspension point can be detected from the consumption of electrical energy. For example, if PU gets stuck in vertical motion or the viscosity of oil becomes more viscous, the stress at suspension point would increase, increasing of the input power. On the contrary, if PU has leakage or experiences a blowout, energy consumption would decrease. Therefore, the working conditions can be interpreted from the energy consumption curve.

By studying the relationship of power, torque, and loading, a mathematical model between loading and electrical power can be established.

$$
\begin{gathered}
E=9549 \frac{N_{r} \eta i}{n_{m}} \\
E=\left[\frac{a}{b} \mathrm{P}-\frac{c}{b} \mathrm{~W}_{b}\left(\cos \theta-\frac{c}{a} \frac{a_{A}}{g}\right)\right] \frac{r \sin a}{\sin \beta}-W_{c}^{\prime} r \sin \varphi
\end{gathered}
$$

The relationship between electrical power and loading is then calculated from the above two formulas.

$$
P=f\left(\mathrm{~N}_{\mathrm{r}}\right)
$$

The displacement curve and surface dynamometer card are interpreted from the crank angle and the electrical power curve, respectively.

Getting dynamic fluid level from surface dynamometer card. Using the Gibbs equation can interpret the pump dynamometer card from the surface dynamometer card ${ }^{12}$. The dynamic fluid level is defined as the height of fluid in the annulus (as shown in Fig. 1).

When the horsehead is at the bottom dead center, the stress at the suspension point $\left(\mathrm{F}_{\mathrm{d}}\right)$ can be expressed as the Eq. (4).

$$
F_{d}=\left[\mathrm{h}_{s} \rho_{l} g+\left(P_{c}-\Delta \mathrm{p}_{s}\right) \times 10^{6}\right] A_{p}
$$
Eq. (5).

When the horsehead is at the top dead center, the stress at the suspension point $\left(F_{u}\right)$ can be expressed as the

$$
F_{u}=\left[L \rho_{l} g+\left(P_{t}+\Delta p_{t}\right) \times 10^{6}\right] A_{p}
$$

The dynamic depth can be calculated as Eq. (6).

$$
L_{f}=L-h_{s}
$$

The resistance of travel $\left(\Delta \mathrm{P}_{\mathrm{t}}\right)$ and affix valve $\left(\Delta \mathrm{P}_{\mathrm{s}}\right)$ can be calculated as the Eq. (7).

$$
\Delta p_{t}=\Delta p_{s}=\Delta p=\frac{\rho_{l} \nu_{f}^{2}}{2 \xi^{2}}
$$




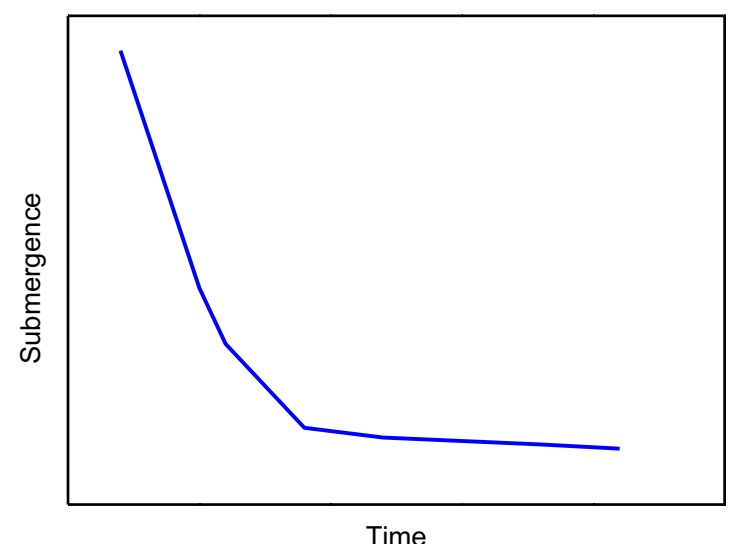

Figure 2. The decreasing curve of submergence during the operation period.

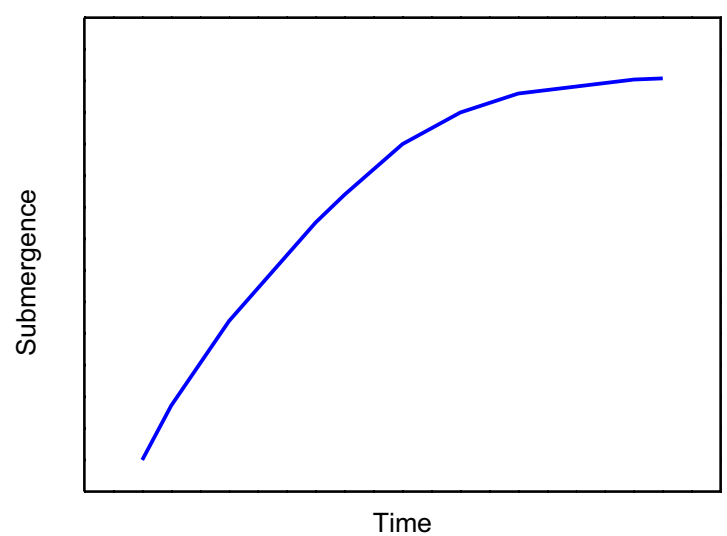

Figure 3. The increasing curve of submergence during the shut-in period.

The Eq. (8) can be solved from Eqs. (4) to (5).

$$
L_{f}=\frac{\left(F_{u}-F_{d}\right)-10^{6}\left(\mathrm{P}_{\mathrm{t}}-\mathrm{P}_{\mathrm{c}}\right) \mathrm{A}_{\mathrm{p}}}{\mathrm{A}_{\mathrm{p}} \rho_{l} g}-\frac{10^{6} \nu_{f}^{2}}{\xi^{2} g}
$$

The Eq. (8) also can be expressed as the following equation.

$$
L_{f}=\frac{\Delta W-10^{6}\left(\mathrm{P}_{\mathrm{t}}-\mathrm{P}_{\mathrm{c}}\right) \mathrm{A}_{\mathrm{p}}}{\mathrm{A}_{\mathrm{p}} \rho_{l} g}-\frac{10^{6} \nu_{f}^{2}}{\xi^{2} g}
$$

Therefore, the dynamic fluid level can be obtained from the loading and displacement of the surface dynamometer card.

Variation law of the submergence. Declining law of the submergence. The submergence depth of a pump in the wellbore fluid equals the depth of the pump subtracting the dynamic fluid depth. The submergence is high when PU starts working. The submergence decreases fast at the beginning of the pumping suction. When the submergence falls to a certain low level, the fluid in the pump would also be at a low degree. The typical decreasing curve of submergence is shown in Fig. 2.

Increasing law of the submergence. During the shut-in period when PU stops working, the increasing law of submergence can be studied through the inflow performance of the well ${ }^{2}$. The pressure difference between surface and bottom-hole forces fluid flowing into the bottom of the well. And raising fluid in the annulus leads to an increase of submergence. The increase of dynamic fluid level further enhances the bottom-hole pressure, which reduces the pressure difference and the fluid flowing into the well. At the end of the shut-in period, the submergence approaches a plateau. It turns out that a longer shut-in period reduces the cumulative production. The submergence of fluid shortage wells firstly increases fast then tends to a stable position in the end. The typical increasing curve during the shut-in period is shown in Fig. 3. 


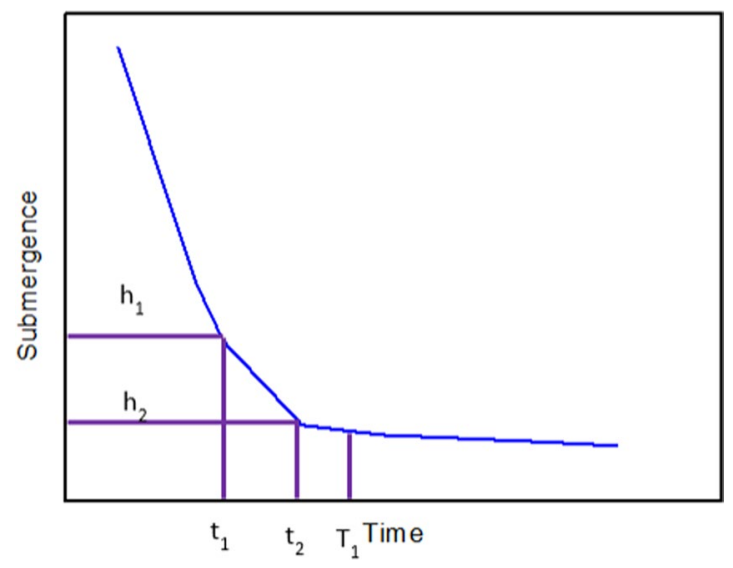

Figure 4. Determination of well-operation period from the decreasing curve of submergence.

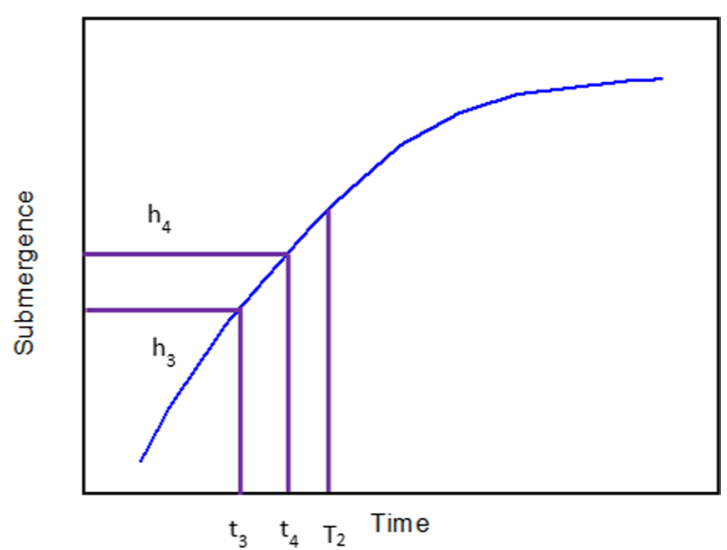

Figure 5. Determination of well-shut-in period from the increasing curve of submergence.

Determination of well-operation period. Once the decreasing curve of submergence is obtained from the monitored electrical curve, the slope of the decreasing region is calculated for determining the optimal period of good operation. The absolute value of the slope within a chosen time interval is calculated since the beginning of the well-operation. This is repeated until the absolute value of the slope is smaller than a pre-determined value ( $\varepsilon$, as described later), and the period till this moment is recorded as the working time $\mathrm{T}_{1}$ for operating the well. The details are shown as follows.

After the obtained submergence decreasing curve is evenly divided into $\mathrm{N}$ intervals, the slope of each interval can be determined from coordinates of two adjacent points are recorded $\left(\left(t_{1}, h_{1}\right)\right.$ and $\left(t_{2}, h_{2}\right)$ in Fig. 4). PU stops working when the absolute value of the slope is small than a certain value $\left(\varepsilon_{1}\right)$, i.e.; $\left|\frac{h_{2}-h_{1}}{t_{2}-t_{1}}\right| \leq \varepsilon_{1}$; and this moment is recorded as $T_{1}$ as shown in Fig. 4. For the first time, the $\varepsilon_{1}$ can be obtained by the former experience, then the $\varepsilon_{1}$ would be corrected by the method in this paper. Thus, the former $\varepsilon_{1}$ would be used to help determine the next new $\varepsilon_{1}$ in the end.

Determination of well-shut-in period. The buildup law of fluid depth can be interpreted from the bottom hole inflow performance. Because of three-phase (oil, gas, and water) in the late production period, here the Petrobras way is introduced to calculate the production ${ }^{13}$.

$$
\begin{gathered}
d p_{w f}=\rho g d h \\
d h=\frac{Q d t}{s}
\end{gathered}
$$

The Eq. (12) can be solved from the Eqs. (10) to (11).

$$
\frac{d p_{w f}}{Q}=\frac{\rho g}{s} d t
$$


Besides, the total liquid output is calculated as Eq. (13).

$$
Q=\left(1-\mathrm{f}_{\mathrm{w}}\right) \mathrm{q}_{\mathrm{oil}}+\mathrm{f}_{\mathrm{w}} \mathrm{q}_{\text {water }}
$$

The total oil output is calculated as Eq. (14).

$$
q_{o i l}=q_{b}+\left(\mathrm{q}_{\text {omax }}-\mathrm{q}_{\mathrm{b}}\right)\left[1-0.2\left(\frac{p_{w f}}{p_{b}}\right)-0.8\left(\frac{p_{w f}}{p_{b}}\right)^{2}\right]
$$

The total water output is calculated as Eqs. (15) and (16).

$$
\begin{gathered}
q_{\text {water }}=J_{1}\left(\mathrm{p}_{\mathrm{r}}-\mathrm{p}_{\mathrm{wf}}\right) \\
J_{1}=\frac{q_{b}}{p_{r}-p_{b}}
\end{gathered}
$$

Finally, Eq. (17) can be obtained from the Eqs. (12) to (16).

$$
-B d t=\frac{d p_{w f}}{W p_{w f}^{2}+Y p_{w f}+Z}
$$

where

$$
\begin{gathered}
B=\frac{\rho g}{s} \\
W=\frac{0.8\left(1-\mathrm{f}_{\mathrm{w}}\right)\left(\mathrm{q}_{\mathrm{omax}}-\mathrm{q}_{\mathrm{b}}\right)}{p_{r}^{2}} \\
Y=\frac{0.2\left(1-\mathrm{f}_{\mathrm{w}}\right)\left(\mathrm{q}_{\mathrm{omax}}-\mathrm{q}_{\mathrm{b}}\right)}{p_{r}}+f_{w} \frac{q_{b}}{p_{r}-p_{b}} \\
Z=-\left[\left(1-\mathrm{f}_{\mathrm{w}}\right) \mathrm{q}_{\mathrm{b}}+\mathrm{f}_{\mathrm{w}} \frac{q_{b}}{p_{r}-p_{b}} \mathrm{p}_{r}\right]
\end{gathered}
$$

and then

$$
\begin{gathered}
p_{w f}=\frac{\frac{2 M}{1+e^{-M(\mathrm{Bt}+C)}}-Y-M}{2 W} \\
M=\sqrt{Y^{2}-4 W Z}
\end{gathered}
$$

The $\mathrm{C}$ in the equation can be solved at the condition of $\mathrm{t}=0$ and the submergence at the beginning of the shut-in period.

Therefore, the relationship between submergence and time is also expressed as follows.

$$
\begin{gathered}
H=\frac{p_{w f}}{\rho g}+H_{\text {pump }}-H_{0} \\
H=\frac{\frac{2 M}{1+e^{-M(\mathrm{Bt}+C)}}-Y-M}{2 W \rho g}+H_{\text {pump }}-H_{0} \\
M=\sqrt{Y^{2}-4 W Z}
\end{gathered}
$$

The submergence buildup curve can be drawn through the mathematical relationship between submergence and time. After the obtained submergence buildup curve is evenly divided into $\mathrm{N}$ intervals, the slope of each interval can be determined from coordinates of two adjacent points are recorded $\left(\left(t_{3}, h_{3}\right)\right.$ and $\left(t_{4}, h_{4}\right)$ in Fig. 5). PU starts working when the absolute value of the slope is small than a certain value $\left(\varepsilon_{2}\right)$, i.e.; $\left|\frac{h_{3}-h_{4}}{t_{3}-t_{4}}\right| \leq \varepsilon_{2}$; and this moment is recorded as $\mathrm{T}_{2}$ as shown in Fig. 4. The calculation method of $\varepsilon_{2}$ is the same as the $\varepsilon_{1}$. 


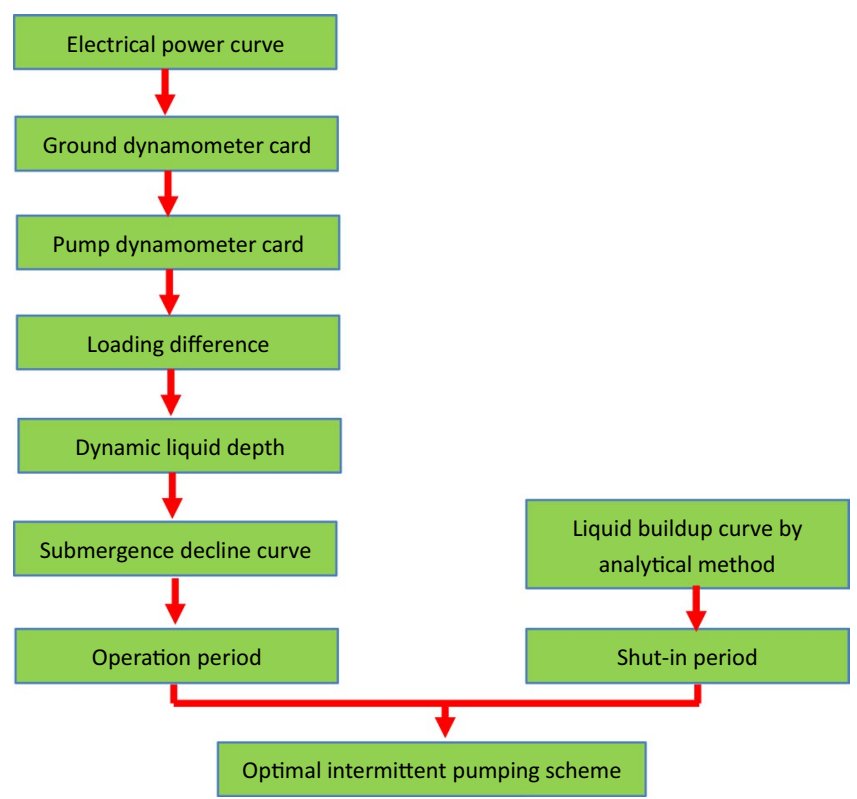

Figure 6. Workflow diagram to determine the optimal intermittent pumping scheme.

\begin{tabular}{|l|l|}
\hline Parameters & Value \\
\hline Tubing Pressure(MPa) & 0.4 \\
\hline Casing Pressure(MPa) & 0.2 \\
\hline Relative Water Density(dimensionless) & 1.0 \\
\hline Relative Gas Density(dimensionless) & 0.64 \\
\hline Relative Oil Density(dimensionless) & 0.8 \\
\hline Pump Depth(m) & 1573 \\
\hline The Diameter of Pump(mm) & 38 \\
\hline Output before Intermittent $(\mathrm{t} / \mathrm{d})$ & 2 \\
\hline Water Cut & 0.4 \\
\hline Stroke (m) & 2 \\
\hline Stroke Speed (min $\left.{ }^{-1}\right)$ & 2.9 \\
\hline Gas-Oil Ratio(dimensionless) & 30 \\
\hline Bubble Pressure $(\mathrm{MPa})$ & 6.5 \\
\hline Depth of Layer $(\mathrm{m})$ & 3000 \\
\hline The Temperature in the Bottom of Well (K) & 353 \\
\hline
\end{tabular}

Table 1. Production data.

\section{Results: Case Study for Field Application}

According to the method mentioned above, a flow chart (Fig. 6) and software have been developed. Inputting the working conditions of a PU, the software can optimize the intermittent pumping scheme in real-time.

A well from Jilin oilfield was chosen as an example. The parameters are shown in Table 1 and Table 2.

After inputting the above parameters to the software, and intermittent pumping scheme has been optimized. The result turns out that the operation period and the shut-in period is 17 and 10 hours, respectively. The current production rate is 1.9 tons per day and the profit is $31,000 \mathrm{RMB}$. Comparing to the former pumping scheme with the operation period of 22 hours and a shut-in period of 8 hours, the production rate is slightly decreased by $5 \%$, but the profit is increased by $25 \%$. This is attributed to the decreased energy expense when the optimized intermittent pumping scheme is applied. In general, this method has a promising future for maximizing the profits from old oilfields with fluid-shortage wells.

\section{Conclusion}

An intermittent pumping scheme for fluid shortage wells has been developed in this study. The variation law of annulus dynamic fluid depth has been studied to design the optimal intermittent pumping scheme. 


\begin{tabular}{|l|l|}
\hline Parameters & Value \\
\hline Inner Diameter of Tubing $(\mathrm{mm})$ & 62 \\
\hline Outer Diameter of Tubing $(\mathrm{mm})$ & 73 \\
\hline Inner Diameter of Casing $(\mathrm{mm})$ & 127.3 \\
\hline Outer Diameter of Casing $(\mathrm{mm})$ & 139.7 \\
\hline Level of Rod(Grade) & 3 \\
\hline Length of First Rod $(\mathrm{m})$ & 732 \\
\hline The Diameter of First Rod $(\mathrm{mm})$ & 22 \\
\hline Length of Second Rod (m) & 675 \\
\hline The Diameter of Second Rod $(\mathrm{mm})$ & 19 \\
\hline Length of Third Rod $(\mathrm{m})$ & 267 \\
\hline The Diameter of Third Rod $(\mathrm{mm})$ & 38 \\
\hline Type of Pumping Unit & CYJ8-3-37HF \\
\hline Motor Power $(\mathrm{kW})$ & 16 \\
\hline Motor Transmission Ratio(dimensionless) & 30.48 \\
\hline Motor Speed (r/min) & 860 \\
\hline Fluid Rates through Valve (m/s) & 0.15 \\
\hline
\end{tabular}

Table 2. Parameters of suction rod and motor.

(1). By studying the relationship between electrical power, torque, and loading, the surface dynamometer card can be interpreted from electrical power curve; this is used to calculate the dynamic fluid level.

(2). During the operation and shut-in periods, both decreasing and rising rates of submergence are fast in the beginning and approaching a plateau in the end. The optimal operation and shut-in time are obtained from the inflection points of their variation curves.

(3). The determination of the shut-in period can be solved by the mathematical relationship between inflow performance and submergence buildup law.

Received: 7 July 2019; Accepted: 15 November 2019;

Published online: 13 February 2020

\section{References}

1. Meng, X. \& Zhang, H. Quantitative Optimization of the Intermittent Production of Low Producing Oil Wells and Its Applications. Journal of Xian Shiyou University (Natural Science Edition) 21(04), 64-68 (2006).

2. Cui, Z. et al. Sucker Rod Pumping System. Petroleum industry press. 301-305 (1992).

3. Jiang, Y. et al. The Study and Application of Intermittent for Oil Wells. Inner Mongolia Petrochemical Industry 12(05), 172-173 (2005).

4. Cimic, M. B. \& Soares, L. Data Acquisition in Pumping Wells. Presented at the 2006 SPE Russian Oil and Gas Technical Conference and Exhibition held in Moscow. Russia, 3-6 October. SPE-101846-MS, https://doi.org/10.2118/101846-MS (2006).

5. Liu, H. The Determination of Intermittent Production System for Low Production Wells. Chinese Technology Information 26(04), 45-47 (2006).

6. Marsh, H. N. Deep-well Pumping in California. SPE Journal 82(1), 75-89, https://doi.org/10.2118/929075-G (1928).

7. Zhang, M. et al. Method for Intermittent Production System in Low Production Well. Drilling \& Production Technology 28(03), 68-70 (2005)

8. Zhou, D. \& Liang, Z. A New Approach for Determining the Reasonable Intermittent Pumping Period for Low Efficiency Well. Drilling \& Production Technology 26(01), 52-55 (2003).

9. Yu, X., He, G. \& Jin, Y. Study on Rationality of Intermittent Pumping System for Pumping Well. Petroleum Geology \& Oilfield Development in Daqing 25(04), 78-79 (2006).

10. Guan, N., Ouyang, H. \& Li, H. Pumping Well Fluid Producing Changing Rule between Pumping Unit is Inefficient. Oil and Gas Field Surface Engineering 25(02), 17-18 (2006).

11. Yan, Q. The Study of Intermittent Cycle for Intermittent Wells. Small Oil field 46(02), 32-35 (2004).

12. Gibbs S. G. A Method of Determining Sucker Rod Pump Performance. U.S. Patent 3343409 (1967).

13. Brown K.E. Lifting Method for Oil Production. Beijing: Petroleum Industry Press: 125-127 (1987).

\section{Acknowledgements}

The authors wish to thank the China University of Petroleum (Beijing) for permission to publish and present this paper.

\section{Author contributions}

The Xingyuan Liang conducted most of the jobs, Fujian Zhou help contact with the case study in the oil field and help with the structure of the paper, Tianbo Liang helps the program and modified the paper.

\section{Competing interests}

The authors declare no competing interests. 
Additional information

Correspondence and requests for materials should be addressed to T.L.

Reprints and permissions information is available at www.nature.com/reprints.

Publisher's note Springer Nature remains neutral with regard to jurisdictional claims in published maps and institutional affiliations.

(c) (i) Open Access This article is licensed under a Creative Commons Attribution 4.0 International License, which permits use, sharing, adaptation, distribution and reproduction in any medium or format, as long as you give appropriate credit to the original author(s) and the source, provide a link to the Creative Commons license, and indicate if changes were made. The images or other third party material in this article are included in the article's Creative Commons license, unless indicated otherwise in a credit line to the material. If material is not included in the article's Creative Commons license and your intended use is not permitted by statutory regulation or exceeds the permitted use, you will need to obtain permission directly from the copyright holder. To view a copy of this license, visit http://creativecommons.org/licenses/by/4.0/.

(C) The Author(s) 2020 